\title{
BALZAC, Guida alla letteratura esoterica
}

\section{Marco Stupazzoni}

\section{OpenEdition \\ Journals}

\section{Edizione digitale}

URL: https://journals.openedition.org/studifrancesi/11854

DOI: 10.4000/studifrancesi. 11854

ISSN: 2427-5856

\section{Editore}

Rosenberg \& Sellier

\section{Edizione cartacea}

Data di pubblicazione: 1 avril 2018

Paginazione: 148

ISSN: 0039-2944

\section{Notizia bibliografica digitale}

Marco Stupazzoni, «BALZAC, Guida alla letteratura esoterica», Studi Francesi [Online], 184 (LXII | I) | 2018, online dal 03 juillet 2018, consultato il 15 novembre 2021. URL: http://journals.openedition.org/ studifrancesi/11854 ; DOI: https://doi.org/10.4000/studifrancesi. 11854

\section{Questo documento è stato generato automaticamente il 15 novembre 2021.}

\section{(c) $(1) \odot$}

Studi Francesi è distribuita con Licenza Creative Commons Attribuzione - Non commerciale - Non opere derivate 4.0 Internazionale. 


\title{
BALZAC, Guida alla letteratura esoterica
}

\author{
Marco Stupazzoni
}

\section{NOTIZIA}

BALZAC, Guida alla letteratura esoterica, a cura di Claudio AscIUTI, Bologna, Odoya, 2016, «Odoya Library», 229 pp.

1 All'interno di questa guida antologico-critica dedicata alla letteratura esoterica e curata da Claudio Asciuti, sono presenti, in luoghi diversi della raccolta, tre brevi capitoli dedicati a Balzac (ai quali si deve aggiungere una sommaria e approssimativa nota biografica sullo scrittore francese: Honoré de Balzac, pp. 264-265) e ad alcuni romanzi della Comédie humaine di matrice esoterica nei quali risulta evidente il legame con le dottrine swedenborghiane. Nel primo di questi capitoli (Swedenborg secondo Balzac, pp. 254-259), C. AScIUTI concentra la sua attenzione su La Peau de chagrin e su Louis Lambert. L'A. considera, in particolare, La Peau de chagrin come un testo ricco di implicazioni simboliche che rimandano all'esoterismo e ritiene che Balzac, muovendosi «a cavallo delle spiegazioni possibili in chiave psicopatologica, e in quelle più propriamente misteriosofiche» (p.258), dissemini tutto il romanzo di segni e di citazioni che spostano l'asse dell'opera dall'assunto naturalista a quello più propriamente magico-esoterico.

2 La ricerca di una nuova dimensione espressiva degli aspetti esoterici del pensiero attraverso le forme della narrazione è rilevabile, secondo l'A., nella Recherche de l'Absolu (1809: dall'Alchimia alla chimica. "La ricerca dell'assoluto", pp.351-354). Storia di un'ossessione, quella del protagonista del romanzo, Balthazar Claës, La Recherche de l'Absolu si configura anche come un breve viaggio nell'alchimia attraverso il quale «la magia dello scrittore [...] si confonderebbe con quella del chimico» (p. 354).

3 L'influenza della teosofia di Swedenborg sulla poetica e sulla filosofia di Balzac si manifesta in maniera esemplare nella trattazione del tema dell'androginia in Séraphîta (L'Androgine swedenborghiano: "Séraphîta" di Honoré de Balzac, pp.375-380). I temi psicologici e teologici che stanno alla base del testo balzachiano sono analizzati in 
maniera alquanto marginale e superficiale dall'A., il quale, a conclusione della sua disamina del romanzo, osserva, a proposito della figura dell'androgino, che «la complessa relazione con il genere femminile, che fu motivo di infiniti problemi all'uomo Balzac, trascende nel Balzac scrittore in questa dissoluzione dei sessi che ci riporta all'Androgine primario di impronta platonica» (p. 380). 